\title{
The Training Mode of Mechanical Talents Based on Professional Engineering Education Certification
}

\author{
Ma Xiaojun \\ College of Mechanical Engineering \\ Jiamusi University \\ Jiamusi, Heilongjiang 154007 \\ mjzx2009phd@163.com \\ Li Chunjiang \\ Dean's office \\ Jiamusi University \\ Jiamusi, Heilongjiang 154007 \\ jmslcj@sohu.com
}

\author{
Zhang Ze \\ Dean's office \\ Jiamusi University \\ Jiamusi, Heilongjiang 154007 \\ sbc8068@126.com \\ Yao Youjie \\ College of Mechanical Engineering \\ Jiamusi University \\ Jiamusi, Heilongjiang 154007 \\ yaoyoujie@126.com
}

\author{
Song Hanjun* \\ Research and Evaluation Center for Higher Education \\ Jiamusi University \\ Jiamusi, Heilongjiang 154007 \\ 13845414622@163.com
}

\begin{abstract}
The purpose of professional certification of higher engineering education is to ensure that China's engineering education system is geared to international standards, and improve the quality of talent training and international perspective. Through the study of the status quo of the allocation of resources for higher engineering education in China, the optimization and integration model of higher engineering education resources and higher engineering education talents training mode of curriculum system, practical ability cultivation, schools-enterprise cooperation and double tutor system based on professional certification system have been constructed. Engineering certification education is vigorously promoted in higher engineering schools, which is of great significance to promoting the scientific development of higher education, deepening education and teaching reform and improving talent training quality.
\end{abstract}

Keywords-engineering education; professional certification; mechanical; talent training mode, resource integration

\section{INTRODUCTION}

Professional engineering education certification has been carried out in many countries, and its role in promoting the development of engineering education has also been confirmed to a large extent and has been widely by the engineering sector and education sector. In 2006, the Ministry of Education officially launched the professional engineering education certification pilot work in conjunction with relevant departments, and decided to start carrying out professional

Financed by Heilongjiang Higher Education Society Project: (16G206) and Jiamusi University teaching research project (2016JW1009, 2017LGL007) together

*Correspondence Author: Song Hanjun(1973-), Professor, master tutor engineering education certification in the country. In March 2006, the Ministry of Education set up an expert committee of professional engineering education certification, including mechanical engineering, electronic engineering, chemical and computer professional pilot working groups, and completed certification pilot work in eight colleges. The amendment of Engineering Education Certification Standard (2015 Edition) was completed by China Engineering Education Professional Certification Association in March 2015. By the end of the year, the certification work of 15 categories, nearly 200 colleges and 656 specialties will be completed. For mechanical specialty, the supplementary standard applies to mechanical engineering, mechanical design, manufacturing and automation, material forming and control engineering, mechanical and electrical engineering, process equipment and control engineering, vehicle engineering, automotive service engineering and other specialties.

With large scale and most specialties, Mechanical Engineering School is the earliest college in Jiamusi University to set up undergraduate specialty. It has 9 undergraduate specialties, including mechanical design, manufacturing and automation, mechanical and electrical engineering, agricultural electrification, vehicle engineering, traffic engineering, energy and power engineering, industrial design, agricultural mechanization and automation, and packaging engineering. Among them, the mechanical design, manufacturing and automation, and agricultural mechanization and automation are provincial key specialties. The college has a modern processing technology training center, a provincial agricultural engineering experimental teaching demonstration center, a field 
work equipment provincial key laboratory, a mechanical engineering school-level experimental teaching demonstration center, and an agricultural engineering post-doctoral workstation.

\section{INTEGRATE HIGHER ENGINEERING EDUCATION RESOURCES}

\section{A. The Status of Higher Engineering Education Resources Allocation}

At present, the gap of higher engineering education resources allocation is large. Whether in terms of faculty or special funds, colleges of different levels in the different regions of the country are big differences, such as "985" and "211" colleges. The engineering education resources allocation of colleges in eastern area is obviously superior to colleges of other levels or other areas. Especially the provincial colleges and application-oriented colleges, because of the expansion of school size, their engineering education resources allocation is in serious shortage, letting corresponding engineering disciplines (majors) develop slowly.

Although the gap of higher engineering education resources allocation is large, because of blind and repeated construction, the schooling and resource allocation of engineering education is of low efficiency on the basis of the existing engineering resources allocation, and resource integration and share is lack of total planning. And there are related laws and regulations on the integration of higher engineering education resources and the corresponding promotion document spirit, as well as the market-oriented criteria of higher engineering education resource allocation.

The investment subjects and channels of higher engineering education investment are relatively simple. The serious shortage of education funding leads to serious shortage in engineering education resources investment in some colleges, or even slows update. Although the market economy has achieved high-speed development, it is difficult for colleges to raise funds from the society or market. Relying on the limit income of financial allocation and school tuition has worsened the total shortage of higher engineering education resources $[1,6]$.

\section{B. Analysis of the Optimization and Integration of Higher Engineering Education Resources}

The integration of higher engineering education resources is a new field of educational science development, which is conducive to the effective use of educational resources and the improvement of educational resources utilization rate. The integration of higher engineering education resources should follow the higher education teaching theory and the objective theory of relationship between education and society or human development, as well as the objective law of the relationship between education and social development. It should follow the basic principles of market economy in higher education resources allocation, give full play to organic bond of planning and market of colleges, and gradually develop into a market economy configuration-led resource allocation model.
The integration of higher engineering education resources should realize the optimal allocation of education resources through the continuous integration. Start with excavation of the school's internal resources, and conduct all-round integration of hardware and software facilities, such as guiding theory for college, campus culture and curriculum system, and give full play to the dominant role of market economy allocation, so as to revitalize the existing educational resources, achieve the coordinated development of education resources in structure, size, quality and efficiency.

\section{The Construction of Higher Engineering Education Resources Optimization and Integration Model}

Under the premise of satisfying the requirements of professional certification system, the integration model of higher engineering education resources mainly refers to the resources integration model which mainly focuses on engineering education subject and social resources (market). The engineering education major resources integration is conducted at two aspects: software and hardware. The auxiliary model of market economy can use inter-school and social education resources to integrate, fully using social resources to train students.

\section{1) Resource Integration Model of Engineering Education} Subject

The resource integration model of engineering education subject uses the existing engineering education resource of school to integrate from software and hardware two aspects. Software: focus on curriculum system and conduct advanced teaching mode such as "MOOC", "Flipped Classroom"; strengthen engineering skills training, and use engineering skill training center to train students' engineering skills and abilities; reform the examination mode; strengthen the construction of teachers. Hardware: implement opening management, and construct the hardware facilities of engineering education subject into a platform management through which achieve the share and intensive management model of hardware facility teaching resources. Change the internal resource structure of engineering education subject, improve the utilization rate of resources, and change the repeated and scattered allocation of resources[2].

\section{2) Social (Market) Resources Integration Mode}

Social (market) resources integration model can introduce the teaching philosophy and education resources integration methods of different higher engineering education schools, absorb and learn from them combining with engineering education practice of the school. And give full play to the advantages of market-oriented resources integration to establish inter-school alliance, school-enterprise alliance and other cooperation models, which make up for the lack of school resources by making full use of social resources to train students' practical ability.

Introduce market-oriented resource allocation mechanism through the educational resources integration of engineering education subjects, so as to realize resource sharing and complementary advantages, stimulate the talent advantages of engineering education subjects, and also help to make up for the market's demand for talents. It provides effective ways and 
methods for personnel training with engineering education background.

\section{The Construction OF Personnel Training Mode}

Rely on engineering education resources such as provincial key specialty, provincial experimental teaching demonstration center, and establish mechanical personnel training model facing engineering education professional certification, namely: combine with the requirements of common standards and mechanical specialties complementary standards in "National Engineering Education Professional Certification Standards (Trial)", and take training mechanical design and manufacturing and its automatic professional engineering application-oriented talents as target, school-enterprise alliance as platform, practical engineering as background, engineering application ability training as principal line to actively carry out theoretical teaching and practical teaching reform, train advanced engineering application-oriented talents with distinctive mechanical industry characteristics and good abilities and qualities who meet the needs of economy development and industrial revitalization. With Jiamusi Institute of Technology being its predecessor, the school has great advantages and distinctive characteristics in mechanical specialties. Therefore, it specially mentions distinctive mechanical industry characteristics in the description of personnel training model[3].

\section{A. Optimize Personnel Training Program and Curriculum System}

Optimize the training program, and highlight the focus. Mechanical professional personnel training program focuses on three characteristics: (1) thick foundation: strengthen the humanities quality, social sciences, business management, teamwork and professional ethics education; strengthen the basic education of natural science such as mathematics, physics, mechanics; strengthen the basic education of engineering and technology such as materials science, computer technology, control theory; strengthen the professional basic education of mechanical engineering such as mechanical design principles and methods, mechanical manufacturing technology foundation, microcomputer principle and application, engineering materials, hydraulic and pneumatic technology. (2) wide caliber: so that students have technical knowledge of a number of professional directions, such as mechanical system design, mechanical modern design introduction, mechanical and electrical transmission control modern manufacturing technology, mold CAD/CAM, and CNC machining technology, machinery products production process and equipment outline, equipment modern design overview. (3) focus on engineering technical ability and innovation ability: in the course of undergraduate education, students will spend the accumulated time of one year in practicing in the enterprise, and significantly improve students' engineering and technical capacity and innovation ability through the actual operation and training in conception, design, development, manufacturing, maintenance and production service of related products in the enterprise.

In accordance with requests such as mechanical professional standard of engineering professional certification system, conduct overall optimization of the curriculum system closely around professional training objectives. Teaching content should focus on the foundation and the future, follow the latest development of disciplines, and introduce new technologies. It should take "quality" and "ability" training as the goal, selects teaching content, involve engineering problems, and conduct dynamic reform and practice on practical teaching links such as curriculum design and graduation design, so as to improve the quality of undergraduate teaching. Through general education and comprehensive quality education modules, mainly cultivate students' humanistic quality, social science, enterprise management, team cooperation and professional ethics and other aspects of quality; discipline basic education and professional education modules mainly strengthen students' basic knowledge of professional skills; practice education module improves students' engineering practice experience, engineering consciousness, engineering quality and engineering ability. Set up a wide range of elective courses, so that students can choose according to their hobbies.

\section{B. Strengthen the School Practice Teaching Links}

Construct practice teaching system which focuses on integrity, designing and application, and combines with extracurricular scientific and technological activities, competitions, professional skills certification, etc. It not only has basic skills training, but also has development and innovation. It changes the current situation of practice teaching which focuses on confirmatory and demonstrates experiments, and breaks the barriers among various professional courses. It strengthens the inter-course cross and infiltration, establishes a series of courses or course group and independent practical training link which has certain flexibility and combines experiment and practice into one. It establishes practical teaching system combining basic skills with professional skills and engineering application ability, and carries out design, manufacture, testing, control and other training programs with practical engineering problems or topics as the goal, so as to meet the need to train students' engineering application and innovation abilities [4].

1) Innovative "platform + project" way to enhance the practical and innovative ability

Set up college students science and technology innovation studio in the school as a platform for students to have innovation training; set up college students innovative training program, and assess 30-50 programs a year. Construct virtual simulation laboratory as a platform for teachers to carry out virtual training; work together with enterprises to establish curriculum research and development project and jointly develop virtual simulation courses. Construct equipment laboratory as a technology development platform for teachers and students, highlighting the mechanical characteristics; relying on the actual technical needs of enterprises, work with enterprises to jointly set up R\&D projects. Establish a intercollege joint laboratory in school.

2) Reform the Experimental Teaching Methods, and Establish Open Experimental Teaching Model

In the professional certification process, teaching method reform is a strong evidence to prove that the standard is reached. Take a variety of measures to organize the reform of 
teaching methods, so as to promote problem-based, case-based, project-based teaching methods. Further optimize the experimental content, and establish hierarchical, modular and open experiment teaching system which combines curricular and extracurricular, teaching and scientific research, including "mechanical cognitive practice" and "product manufacturing basic engineering training" - "mechanical basic experiment" and "mechanical basis integrated curriculum design" "engineering integrated practice" and "research innovation practice". It conducts all-open teaching, and train students' practical ability and innovation ability through design and manufacturing of simple products and organization, virtual design and manufacturing technology training, mechanical and electrical products' structure, control, design, innovation and manufacture[5].

3) Improve the proportion of experimental teaching, and highlight practical ability training

Improve the proportion of experimental teaching through the revision of personnel training programs, broadening space for practice teaching. Combined with the teacher's research projects, production practice needs and college students research and training program, focus on the development of integrated design and research innovative experimental projects, so as to improve students' practical ability. Make full use of the school experimental teaching demonstration center and practice teaching base outside the school, increase the proportion of students practice, and fully cultivate students' practical ability and ability to solve practical production problem on site, so that students can be connected to the actual production as soon as possible.

\section{Deepen the School-Enterprise Joint Training}

To meet the requirements of enterprises on the mechanical specialties, establish school-enterprise co-training mode and operation mechanism. School and enterprise establish corresponding organization, jointly develop training standards, jointly develop and carry out training programs. Based on theoretical application capacity and engineering practice ability, strengthen innovation and entrepreneurship education, ensuring that the objectives of school-enterprise joint training are implemented in detail. Choose the counterpart enterprise to establish long-term teaching practice cooperative relations. Part of professional courses and practice links in the four years of undergraduate studying are mostly completed in enterprises. Practice link is carried out with enterprise's practical issues such as enterprise product development and technology improvement, effectively improve students' ability to learn and apply knowledge, make innovation and communicate.

\section{Implement Dual Tutor System}

School-enterprise joint training adopts dual tutor system. Teachers with senior title in school act as intramural tutor, and experts with senior technical title or technician or management experts with rich practical experience and strong sense of responsibility in enterprise as extramural supervisor. At the same time, a joint steering group was set up as needed to conduct more targeted guidance.

Clearly requires the school teachers must have 2 months' enterprise engineering practice background per year. The formation of engineering practice background can be achieved by undertaking scientific research project which solves enterprise's practical engineering problems, putting on field practice, hold internships on site together with students. Enterprise teacher must worked more than 5 years in the front line, have engineer title or above, and engage in specific works such as mechanical design, technology, manufacturing, operation and management. At the same time, they must have good ideological and moral qualities, cultural literacy, professional quality, engineering quality, physical and mental support, and expression, communication and teamwork ability. Regularly organize professional teachers and young enterprise teachers to participate in personnel training seminars together, jointly improving the teaching and professional level. At the same time, actively create good conditions for the growth of young enterprise teachers, and enhance professional standards through short-term study, pursuing degrees, etc.

\section{REFERENCES}

[1] Jiang Chen. Mechanical Specialty Teaching Model Reform Facing International Engineering Education Certification [J]. Education Science \& Culture, 2014,10:69-70.

[2] Zhao Tuo, Ren Hawei, Zhang Yi, Wang Ya, Zhao Ping, Chen Xiaoxian, Liu Xiaofeng, Zhang Bingyun, Zhang Baigang. Exploration and Practice of Talent Training Model of Food Science and Engineering Specialty in Local Engineering Colleges with Engineering Education Specialty Certification as Guidance [J ]. Grain and Oil Processing (electronic version), 2014, 12:69-71+75.

[3] Zhang Fang, Huang Fang, Zhang Huidong, Chen Qifan, Wang Qiulan, Hong Zhe, Liu Fei.Study and Practice of Applied Talents Training Mode in Line with Engineering Education Professional Certification - Taking the Chemical Engineering and Technology Specialty of Liaodong University as an Example[J]. Shandong Chemical Industry, 2015,17:131-132 + 136.

[4] Li Lingling, Zhao Xuemin. Computer Professional Personnel Training Mode Exploration under The Background of Engineering Education Professional Certification[J]. Journal of Management School, Zhengzhou Institute of Aeronautical Industry (Social Science Edition), 2013,06:181-184.

[5] Yang Lin, Yang Qihua. Construction and Practice of Applied Talents Training Mode in Local Colleges and Universities Based on Engineering Education Professional Certification and Excellence Engineer Training Program [A]. Wuhan University, Scientific Research Publishing. Proceedings of Conference on Creative Education (CCE2012) [C] .Wuhan University, Scientific Research Publishing,, 2012: 3.

[6] MA Xiaojun, Su Guizhang, Li Chunjiang, Ma Jigang, Zhang Ze. Integration of Higher Engineering Education Resources Based on Professional Certification System [J]. China Science and Technology Information 